\title{
Outstanding features of COVID-19 overlapping primary immunodeficiency in children
}

Qi Jiang ${ }^{1}$, Qian Yang ${ }^{1}$, Man Man Niu${ }^{1}$, Rui Xue $\mathrm{Li}^{1}$, and Peng $\mathrm{Hu}^{1}$

${ }^{1}$ First Affiliated Hospital of Anhui Medical University Department of Paediatrics

January 20, 2022

\section{Hosted file}

Outstanding features of COVID-19 overlapping PID.doc available at https://authorea.com/ users/456245/articles/553359-outstanding-features-of-covid-19-overlapping-primaryimmunodeficiency-in-children 